\title{
GCU
}

Glasgow Caledonian

University

University for the Common Good

\section{Quantitative analysis of terahertz spectra for illicit drugs using adaptive-range micro- genetic algorithm}

Chen, Yi; Ma, Yong ; Lu, Zheng ; Peng, Bei ; Chen, Qin

Published in:

Journal of Applied Physics

DOI:

$10.1063 / 1.3624737$

Publication date:

2011

Document Version

Publisher's PDF, also known as Version of record

Link to publication in ResearchOnline

Citation for published version (Harvard):

Chen, Y, Ma, Y, Lu, Z, Peng, B \& Chen, Q 2011, 'Quantitative analysis of terahertz spectra for illicit drugs using adaptive-range micro-genetic algorithm', Journal of Applied Physics, vol. 110, no. 4, pp. 043101.

https://doi.org/10.1063/1.3624737

\section{General rights}

Copyright and moral rights for the publications made accessible in the public portal are retained by the authors and/or other copyright owners and it is a condition of accessing publications that users recognise and abide by the legal requirements associated with these rights.

Take down policy

If you believe that this document breaches copyright please view our takedown policy at https://edshare.gcu.ac.uk/id/eprint/5179 for details

of how to contact us. 


\title{
Quantitative analysis of terahertz spectra for illicit drugs using adaptive-range micro-genetic algorithm
}

\author{
Yi Chen, ${ }^{1,2, a)}$ Yong Ma, ${ }^{3}$ Zheng Lu, ${ }^{4}$ Bei Peng, ${ }^{2}$ Qin Chen ${ }^{3}$ \\ ${ }^{1}$ Department of Mechanical Engineering, University of Glasgow, Glasgow, G12 8QQ, United Kingdom \\ ${ }^{2}$ School of Mechatronics Engineering, University of Electronic Science and Technology of China, \\ Chengdu, 611731, People's Republic of China \\ ${ }^{3}$ Department of Electronics and Electrical Engineering, University of Glasgow, Glasgow, G12 8LT, \\ United Kingdom \\ ${ }^{4}$ Department of Electronic and Information Engineering, Nanjing University of Aeronautics and Astronautics, \\ Nanjing, 210016, People's Republic of China
}

(Received 23 March 2011; accepted 10 July 2011; published online 17 August 2011)

\begin{abstract}
In the field of anti-illicit drug applications, many suspicious mixture samples might consist of various drug components-for example, a mixture of methamphetamine, heroin, and amoxicillin -which makes spectral identification very difficult. A terahertz spectroscopic quantitative analysis method using an adaptive range micro-genetic algorithm with a variable internal population (ARVIP $\varepsilon \mu \mathrm{GA}$ ) has been proposed. Five mixture cases are discussed using ARVIP $\varepsilon \mu \mathrm{GA}$ driven quantitative terahertz spectroscopic analysis in this paper. The devised simulation results show agreement with the previous experimental results, which suggested that the proposed technique has potential applications for terahertz spectral identifications of drug mixture components. The results show agreement with the results obtained using other experimental and numerical techniques. (C) 2011 American Institute of Physics. [doi:10.1063/1.3624737]
\end{abstract}

\section{INTRODUCTION}

Illicit drug control is one of the most widely discussed research areas related to social safety and security, and in this area terahertz time-domain spectroscopy (THz-TDS) is a highly demanded alternative. ${ }^{1-10}$ The terahertz $(\mathrm{THz})$ region of the electromagnetic spectrum sits between the microwave and the midinfrared region and is usually defined by the frequency range of $0.1-10 \mathrm{THz}$, that is, $10^{12}$ cycles per second, as shown in Fig. 1. In the $\mathrm{THz}$ region, most of the large organic molecules have characteristic absorption behaviors that have recently attracted the interest of many researchers due to the potential applications in many areas such as noninvasive security screening, chemical agent identification, and pharmaceutical and biological sensing. ${ }^{11-16}$ Terahertz spectroscopic studies of illegal drugs and explosives have been reported recently due to the emerging demand for security and anti-crime applications. ${ }^{17-23}$ In this paper, the terahertz spectra of several illicit drug samples are analyzed using THz-TDS, including methamphetamine (MA), 3,4methylenedioxyamphetamine (MDA), 3,4-methylenedioxymethamphetamine (MDMA), and heroin, with the assistance of improved micro-genetic algorithms.

The first implementation of micro-genetic algorithms ( $\mu \mathrm{GA}$ ) was proposed by Krishnakumar ${ }^{24}$ in 1989 and adopted an elitist strategy to duplicate the current best individuals found in the generation $t$ in the next generation $t+1$. Then, a few researchers also reported their works on $\mu \mathrm{GA}$ utilizing a small population and a reinitialisation process along with the overall genetic algorithm evolution process. ${ }^{25-30}$ Generally,

\footnotetext{
a) Author to whom correspondence should be addressed. Electronic mail: leo.chen.yi@live.co.uk.
}

there are two types of population strings: the external population string $\left(P_{E}\right)$ and the internal population string $\left(P_{I}\right) ; P_{E}$ archives the best individuals of the Pareto optimal set, and $P_{I}$ generates the evolutional data of diversity. In the traditional $\mu \mathrm{GA}$, the size of $P_{I}$ is fixed; users need to use "try-error" loops to find the suitable $P_{I}$ size for different applications, which leads to a relatively low computational efficiency. In order to improve the adaptive ability, in this paper we propose an adaptive range micro-genetic algorithm with a variable internal population (ARVIP $\varepsilon \mu \mathrm{GA})$, the internal population of which has a variable size.

In this paper, the ARVIP $\varepsilon \mu \mathrm{GA}$ will be utilized to compare the $\mathrm{THz}$ spectroscopic signature of each component and estimate the possibility of the combinational components of a drug mixture, and we demonstrate the agreement and improvements of the results obtained compared with the previous experimental analysis. ${ }^{31-36}$

\section{ADAPTIVE RANGE MICRO-GENETIC ALGORITHM WITH VARIABLE INTERNAL POPULATION}

The ARVIP $\varepsilon \mu \mathrm{GA}$ work-flow is given in Fig. 2. There are two cycles in the overall framework, the "internal cycle" and the "external cycle," which are terminated by the conditions of the "max internal generations" and the "max generations," respectively.

For the internal cycle, as stated in Eq. (1), the internal population $P_{I}$, which is used as the source of diversity of the internal loop, is made up of two sub-sections: the replaceable section $P_{I R}$ and the non-replaceable section $P_{N R}$. Equation (2) defines the size of $P_{I R}$ at generation $t$, which is calculated using the size of $P_{I R}$ at generation $t-1$ plus ("+") the off-size of the replaceable section $\Delta P_{I R}$ at generation $t-1$, that is, the 


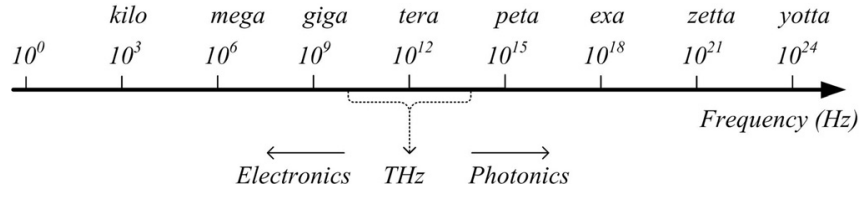

FIG. 1. THz range in the electromagnetic spectrum.

current generation $P_{I R}$ as decided by the last generation $P_{I R}$ and $\Delta P_{I R}$.

$$
\begin{gathered}
P_{I}(t)=P_{I R}(t)+P_{I N}(t) \\
P_{I R}(t)=P_{I R}(t-1)+\Delta P_{I R}(t-1)
\end{gathered}
$$

The off-size replaceable population is proportional to the size of the original internal population $P_{I}$; this is stated in Eq. (3), where $\lambda$ is a reproduction rate set by users.

$$
\Delta P_{I R}=\lambda P_{I}
$$

Similar to the basic $\mu \mathrm{GA}$, the ARVIP $\varepsilon \mu \mathrm{GA}$ work-flow includes three parts: fitness function definitions; encoding and decoding definitions; and genetic operator definitions, in which the genetic operators usually include selection, crossover, and mutation (optional for $\mu \mathrm{GA}$ ). In this proposed method, there is also an "adaptive block" that contains three sub-blocks: "update population statistics," "range adaptation," and "elitist-random reinitialisation." This design of the adaptive block has been discussed and applied in an airfoil optimization problem by Szöllös et al. ${ }^{30}$

For the external cycle, it is an usual loop of $\mu \mathrm{GA}$ : each of the external cycles goes with a full internal cycle numbered by the max internal generations. In an evolutional work-flow, ARVIP $\varepsilon \mu \mathrm{GA}$ creates a population of solutions $\left(P_{E}\right)$, genetic operators such as selection and crossover are applied in order to find better results matching the objective error limits.

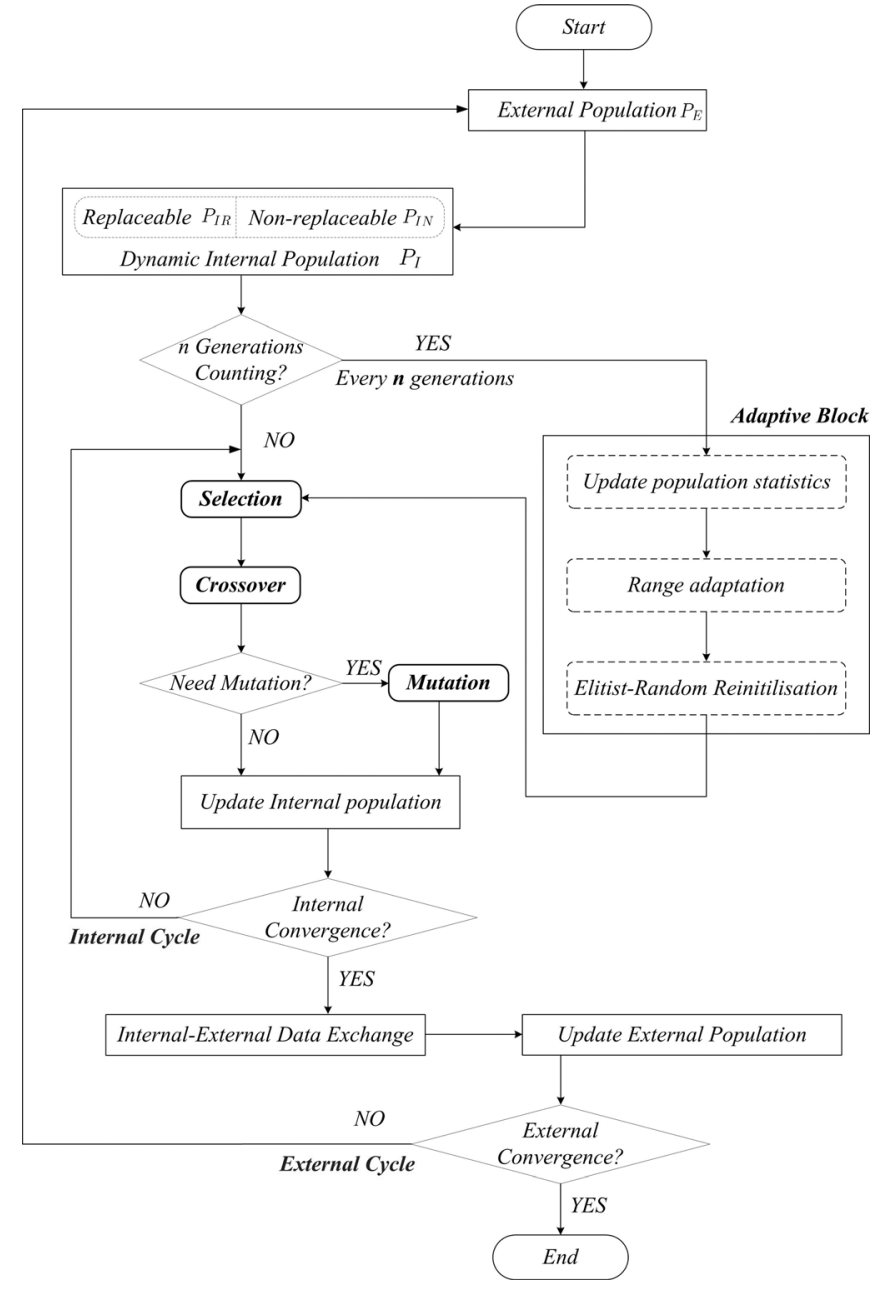

FIG. 2. ARVIP $\epsilon \mu \mathrm{GA}$ work-flow.

\section{THZ-TDS EXPERIMENT CONFIGURATION}

A typical THz-TDS experimental configuration is given in Fig. 3, in which a femto-second pulsed laser source is

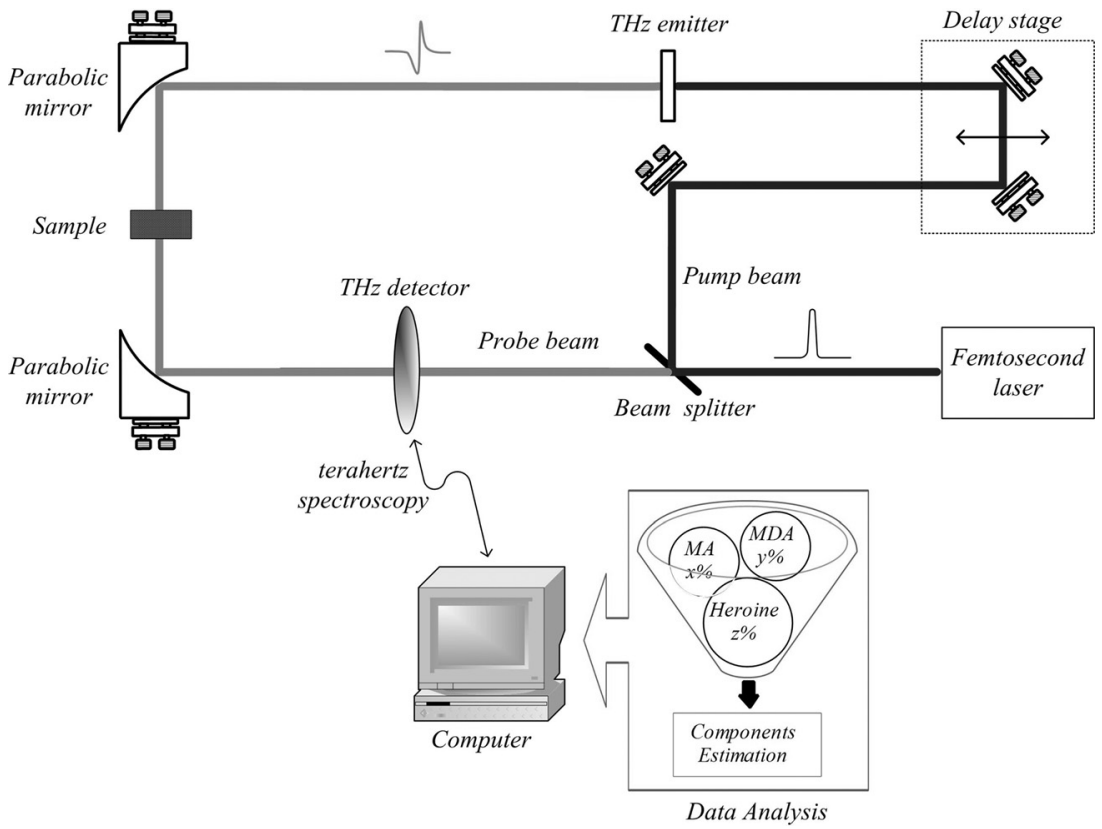

FIG. 3. Schematic of a THz-TDS experiment setup (Refs. 12 and 20). 


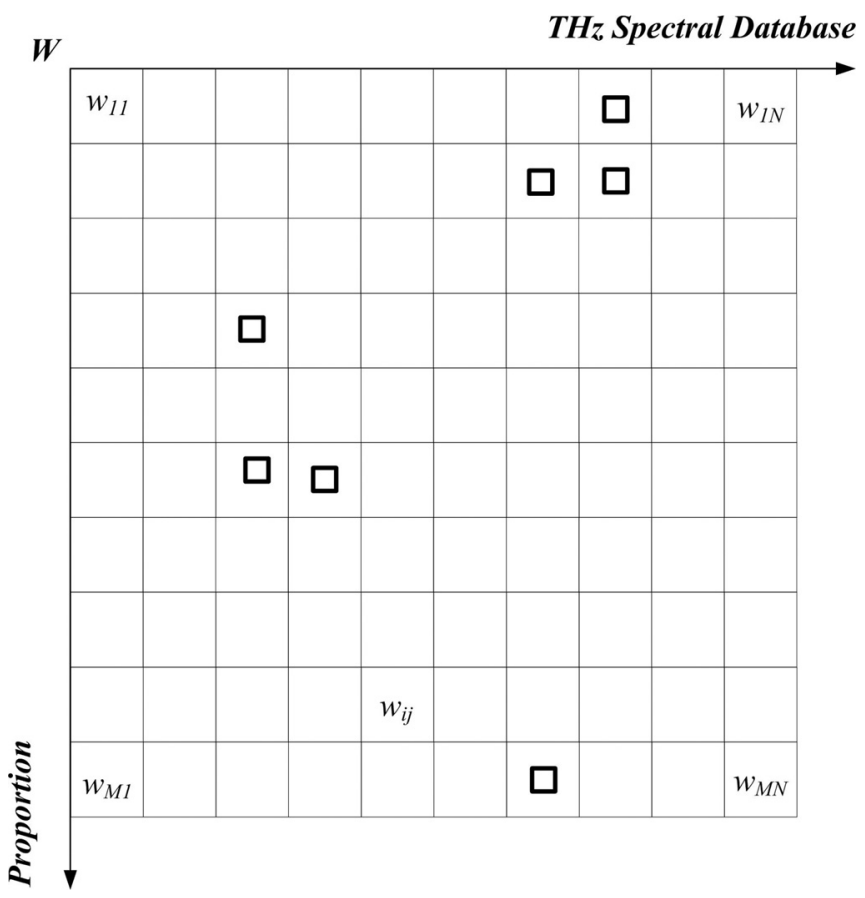

FIG. 4. Components determination statement.

used to generate a $\mathrm{THz}$ beam via a $\mathrm{THz}$ emitter, which can be either non-linear crystal $^{5,6,19}$ or a semiconductor photoconductive antenna (PCA). ${ }^{8,9}$ A parabolic mirror leads the $\mathrm{THz}$ beam onto the sample, and the other parabolic mirror collects the transmitted $\mathrm{THz}$ beam from the sample cell and then focuses it onto the $\mathrm{THz}$ detector. The probe beam detects the $\mathrm{THz}$ pulse via either electro-optic sampling in the non-linear crystal ${ }^{5,6}$ or the photo-conductive effect in the PCA. ${ }^{8,9}$ Consequently, the data analysis of the THz spectroscopy is performed by the specially designed ARVIP $\varepsilon \mu \mathrm{GA}$ computing program.

\section{COMPONENTS DETERMINATION STATEMENT}

In order to quantise the possible combination of the components, a weight matrix $W$ is defined as the "statement," the ele- ment of which is expressed as $w_{i, j} \in\{0,1\}, i=1,2, \ldots, M$, $j=1,2, \ldots, N$, and $M \times N$ are the dimensions of the matrix $W$. As stated in Eq. (4), the value of $w_{i, j}$ indicates the state for the current component of specimen type $j$ with its proportion $i$ as a percentage. There are two types of values ( 0 or 1$)$ that can be assigned to each $w_{i, j} . w_{i, j}=1$ is the "active" state, which indicates that the current mixture consists of the combination of the specimen type $j$ with the weight ratio $i$ and will be taken to $\mu \mathrm{GA}$ fitness assessment. $w_{i, j}=0$ is the "non-active" state, which will not be taken into the $\mu \mathrm{GA}$ process. Practically, the active and nonactive states are marked as $\square$ and empty (void) in a statement. For example, $w_{1,5}=1$ and $w_{9,2}=1$ indicate that the current mixture is combined with specimen type No. 5 in $1 \%$ and specimen type No. 2 in $90 \%$.

$$
w_{i, j}=\left\{\begin{array}{cc}
1 & W \\
0 & \text { void }
\end{array}\right.
$$

$W(10 \times 10)$ shows that there are 10 choices of proportions as a percentage $(M=10)$ and 10 types of specimens in the $\mathrm{THz}$ database $(N=10)$. For a $10 \times 10$ statement $W(10 \times 10)$ case, as shown in Fig. 4, the row number (horizontal axis) represents the possible drug specimen in the mixture and the number of possible drug specimens is $N$. The vertical axis of the statement $W$ represents the possible concentration of the corresponding specimen in terms of the percentage. The increment in the vertical axis is $10 \%$; therefore, the resolution of the above statement is $10 \%$. In this $W(10 \times 10)$ case, the resolution of the concentration will be $10 \%$, as the increment of the matrix $M \times N$ is $10 \%$. The higher dimension $M$ provides a higher resolution of the statement, the time complexity of which $O(2)$ shows that the larger the size of $M$, the longer the central processing unit (CPU) time each the genetic algorithm simulation requires. Specifically, the $M$ can be estimated by Eq. (5), where $r_{0}$ is the required resolution as a percentage. In this $W(10 \times 10)$ case, $r_{0}=10 \%$ and $M=100 / 10=10$.

$$
M=\frac{100}{r_{0}}
$$

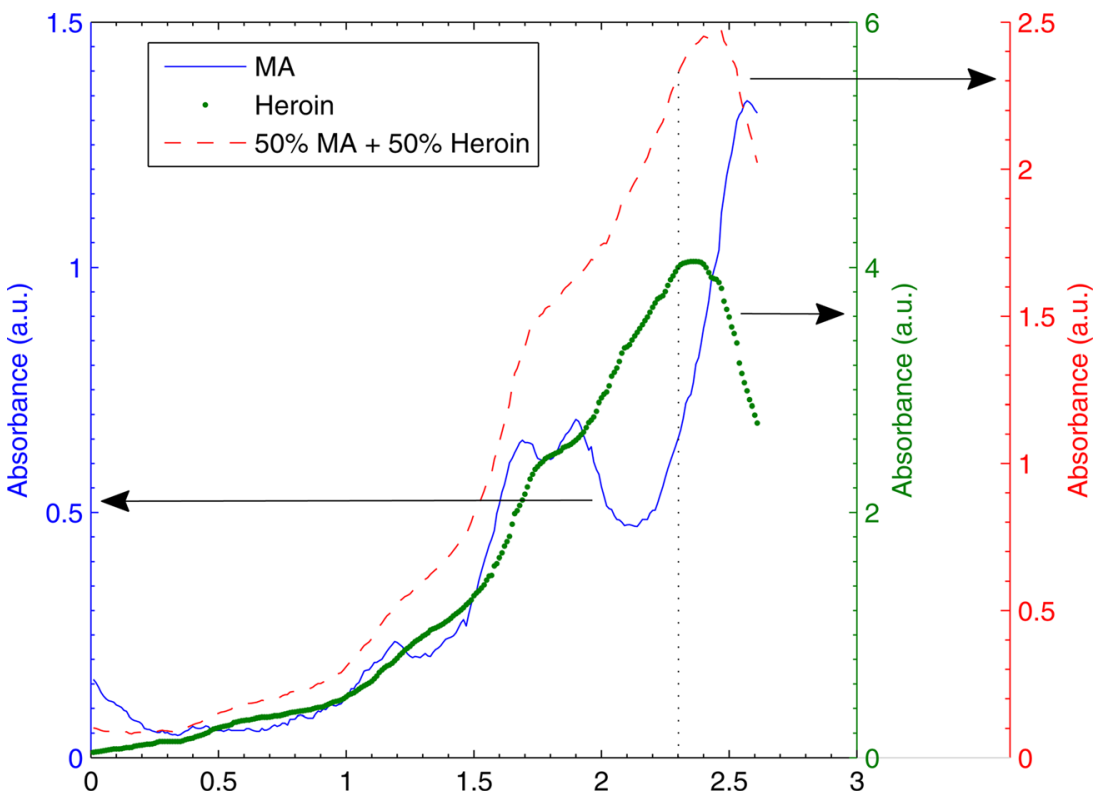

FIG. 5. (Color online) Mixture sample: 50\% MA and $50 \%$ heroin. 
TABLE I. Terahertz spectroscopic database (Refs. 20, 23, 31-35, 41-44).

\begin{tabular}{|c|c|c|c|c|c|c|}
\hline Record & Item & $\begin{array}{c}\text { Case } 1 \\
(\%)\end{array}$ & $\begin{array}{c}\text { Case2 } \\
(\%)\end{array}$ & $\begin{array}{c}\text { Case } 3 \\
(\%)\end{array}$ & $\begin{array}{c}\text { Case4 } \\
(\%)\end{array}$ & $\begin{array}{c}\text { Case } 5 \\
(\%)\end{array}$ \\
\hline 1 & 1,3-DNB & & & & & \\
\hline 2 & TNT & & & & & \\
\hline 3 & RDX & & & & & \\
\hline 4 & PETN & & & & & \\
\hline 5 & HMX & & & & & \\
\hline 6 & 4-NT & & & & & \\
\hline 7 & 2-A-4,6-DNT & & & & & \\
\hline 8 & 2,4-DNT & & & & & \\
\hline 9 & 2,6-DNT & & & & & \\
\hline 10 & 4-A-2,6-DNT & & & & & \\
\hline 11 & Tetryl & & & & & \\
\hline 12 & $1,3,5-\mathrm{TNB}$ & & & & & \\
\hline 13 & 3,5-DNT & & & & & \\
\hline 14 & 1,4-DNB & & & & & \\
\hline 15 & D-ribose & & & & & \\
\hline 16 & D-glucose & & & & & \\
\hline 17 & $\alpha$-lactose & & & & & \\
\hline 18 & $\beta$-lactose & & & & & \\
\hline 19 & benzoic acid & & & & & \\
\hline 20 & o-toluic acid & & & & & \\
\hline 21 & m-toluic acid & & & & & \\
\hline 22 & p-toluic acid & & & & & \\
\hline 23 & MA & 90 & & & & 20 \\
\hline 24 & MDA & & 90 & & & 20 \\
\hline 25 & MDMA & & & 90 & & 20 \\
\hline 26 & Heroin & & & & 90 & 20 \\
\hline 27 & Penicillin V & & & & & 10 \\
\hline 28 & Amoxicillin & & & & & 10 \\
\hline
\end{tabular}

The mixture sample spectrum is calculated by summing up the spectra of all specimens $(j)$ multiplied by the corresponding proportional factor $(i)$. In Fig. 5, a drug mixture sample with $50 \% \mathrm{MA}$ and $50 \%$ heroin is demonstrated; the solid line, dotted line, and dashed line are the $\mathrm{THz}$ absorption data of MA, heroin, and a $50 \% \mathrm{MA}+50 \%$ heroin mixture, respectively.

For the sample components with spectra that are not recorded in the current version of the database, there are mainly three ways to deal with this problem: (1) standardizing experimental conditions such as the sample, temperature, and frequency range; (2) academic or professional $\mathrm{THz}$ database sharing projects ${ }^{37,38}$; and (3) timely updating of the $\mathrm{THz}$ database to a higher version for the quantitative analysis software.

\section{FITNESS FUNCTION DEFINITION}

The coefficient of determination $\left(R^{2}\right)$ is taken as a quantity for the quantitative analysis, which measures the proportion of total components in the mixture by the ARVIP $\varepsilon \mu \mathrm{GA}$.

$R^{2}$ is defined by Eq. (6), ${ }^{39,40}$ in which $S S_{t}$ and $S S_{e}$ are the total corrected sum of squares and the residual sum of squares, $\vec{y}_{i}$ represents the spectral data calculated by ARVIP $\varepsilon \mu \mathrm{GA}$ over the evaluating process, $\overrightarrow{\hat{y}}_{i}$ represents the actual spectral data obtained experimentally, $\vec{y}_{i}$ is the mean value of the calculated data $\vec{y}_{i}$, and $k$ is the number of observations. In this context, $R^{2}$ is selected as the fitness function $J$ to evaluate the ARVIP $\varepsilon \mu \mathrm{GA}$ quantitative analysis; larger values of $R^{2}$

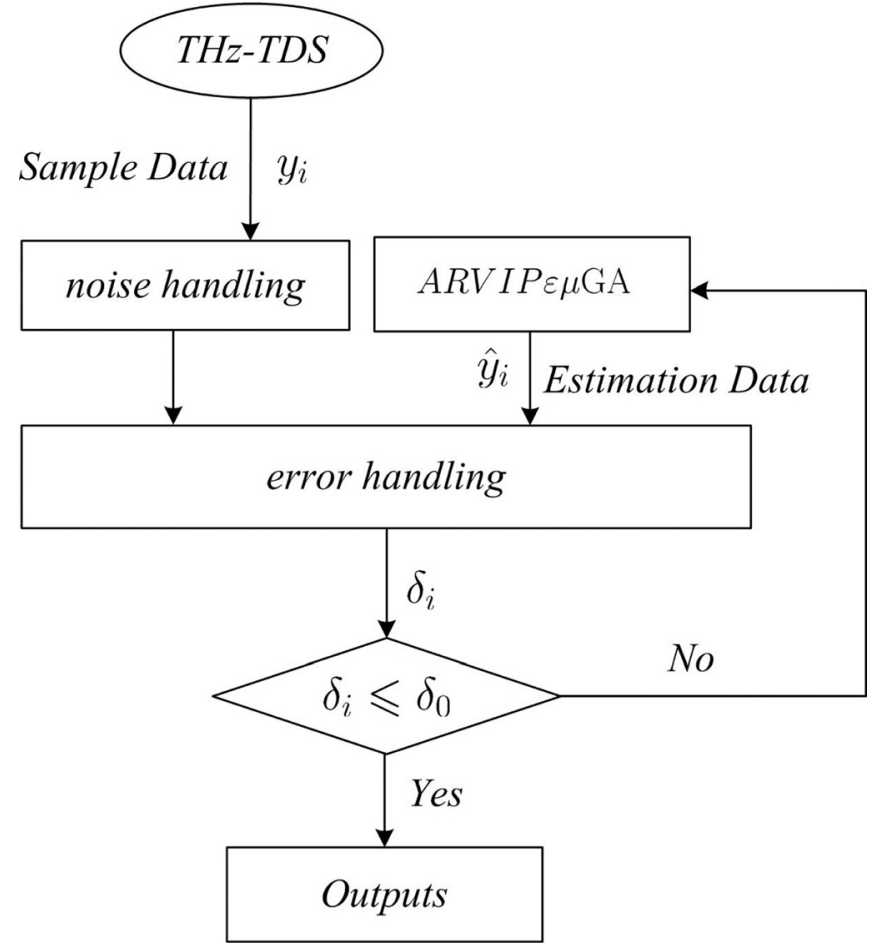

FIG. 6. Noise analysis work-flow.

indicate better approaching within the data. For a case of $W(M \times N)$, there are $N$ types of candidates, and the sample size $k$ of each type of candidate is decided by the experimental data obtained from the THz-TDS experimental studies.

$$
R^{2}\left(\vec{y}_{i}, \overrightarrow{\hat{y}}_{i}\right)=1-\frac{S S_{e}}{S S_{t}}=1-\frac{\sum_{i=1}^{k}\left(\vec{y}_{i}-\overrightarrow{\hat{y}}_{i}\right)^{2}}{\sum_{i=1}^{k}\left(\vec{y}_{i}-\vec{y}_{i}\right)^{2}}
$$

The ARVIP $\varepsilon \mu \mathrm{GA}$ compares the calculated spectral characteristics (absorbance) with the actual spectral characteristics in the $\mathrm{THz}$ database by the fitness function $J$, as shown in Eq. (7), where $F\left(w_{i, j}\right)$ is the weighted absorbance calculated by the lookup function $F$ as given in Eq. (8); $F\left(w_{0}\right)$ are the actual spectral data of the drug mixture sample as given in Eq. (9); $\sum_{i=1}^{M} \sum_{i=1}^{N} F\left(w_{i, j}\right)$ produces the spectral data, which are obtained by summing the overall $M \times N$ element of the $W$ matrix; $w_{0}$ is the given sample element, the components

TABLE II. Parameters for ARVIP $\varepsilon \mu \mathrm{GA}$.

\begin{tabular}{lc}
\hline \hline Max generations & 1000 \\
Max internal generations & 6 \\
Crossover probability & 0.8 \\
Mutation probability & 0.001 \\
$P_{I}$ internal population & 4 \\
$P_{E}$ external population & 100 \\
Selection operator & Tournament \\
Crossover operator & Single point \\
Mutation operator & Single point \\
Encoding method & Binary \\
Tournament size & 2 \\
\hline \hline
\end{tabular}


TABLE III. $R^{2}$ comparison for one of the selected simulation results.

\begin{tabular}{lccccc}
\hline \hline & Case1 & Case2 & Case3 & Case4 & Case5 \\
\hline ARVIP $\mu$ GA & 0.9501 & 0.9530 & 0.9509 & 0.9448 & 0.9592 \\
Reference calculation & 0.7051 & 0.7420 & 0.5009 & 0.0853 & \\
(Refs. 31-36) & & & & & \\
\hline \hline
\end{tabular}

of which are to be compared with the specimens in the $\mathrm{THz}$ database and then determinated; and $w_{i j}$ are the ARVIP $\varepsilon \mu \mathrm{GA}$ generated elements of the statement over the evaluation process.

$$
\begin{gathered}
\text { Maximise: } J=R^{2}\left(\sum_{i=1}^{M} \sum_{j=1}^{N} F\left(w_{i, j}\right), F\left(w_{0}\right)\right) \\
F\left(w_{i, j}\right)=w_{i, j} D(j) P_{e r}(i) \\
F\left(w_{0}\right)=D_{0}
\end{gathered}
$$

$F$ is the lookup function, which can return the weighted spectroscopic data (absorbance) from the $\mathrm{THz}$ spectroscopic database by the input statements $w_{i j}$ and $w_{0}$, as given in Eqs. (8) and (9), where $D(j)$ is the $j$ th type THz spectroscopic data vector, $P_{e r}(i)$ is the percentage index for the current proportion, and $D_{0}$ is the measured $\mathrm{THz}$ spectroscopic data vector.

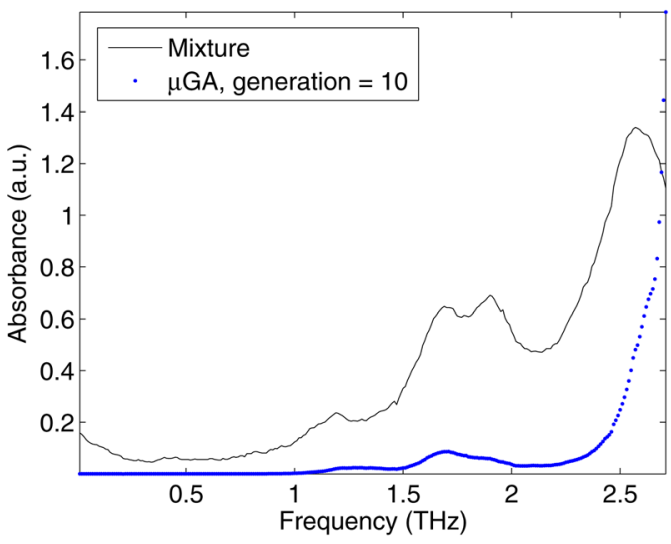

(a) $\mathrm{THz}$ spectra comparison @ generation $=10$

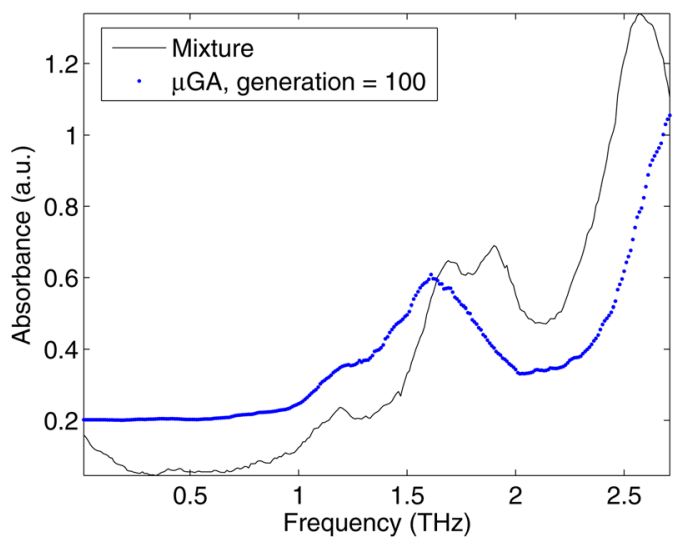

(c) $\mathrm{THz}$ spectra comparison @ generation $=100$

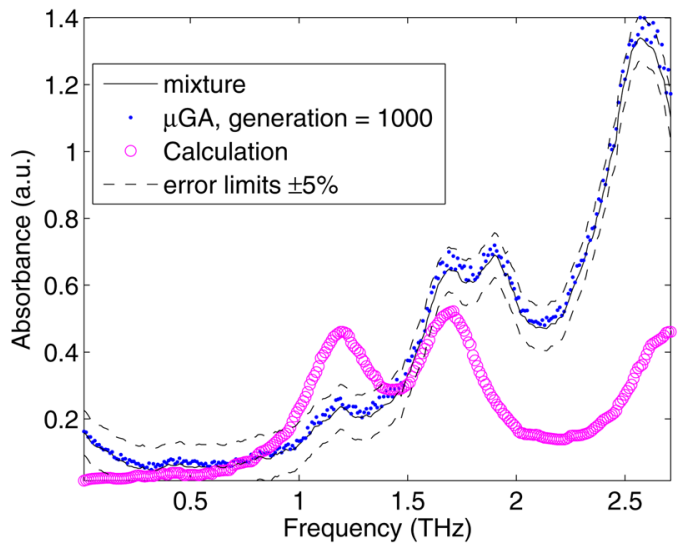

(e) $\mathrm{THz}$ spectra comparison @ generation $=1000$

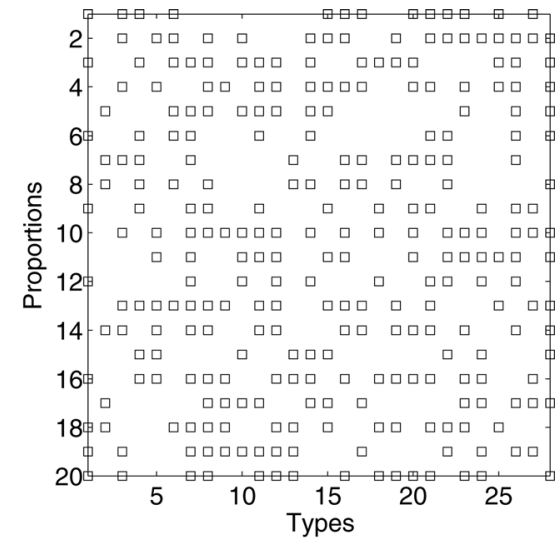

(b)Statement @ generation = 10

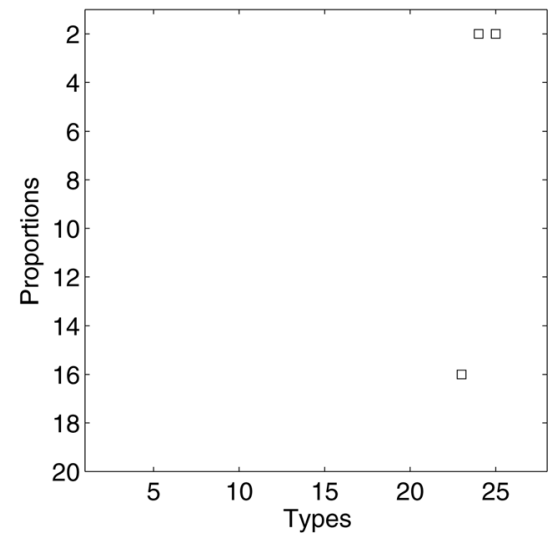

(d)Statement @ generation = 100

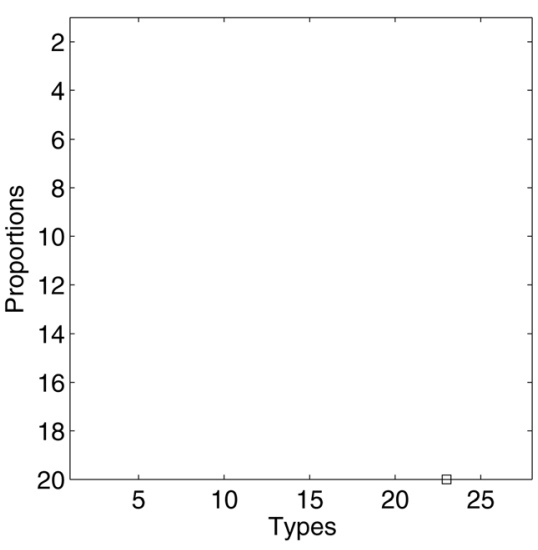

(f)Statement @ generation = 1000
FIG. 7. (Color online) Case1: MA, statement distribution and corresponding terahertz spectra at various generations: (a),(b) 10 generations, (c),(d) 100 generations, and (e),(f) 1000 generations. 


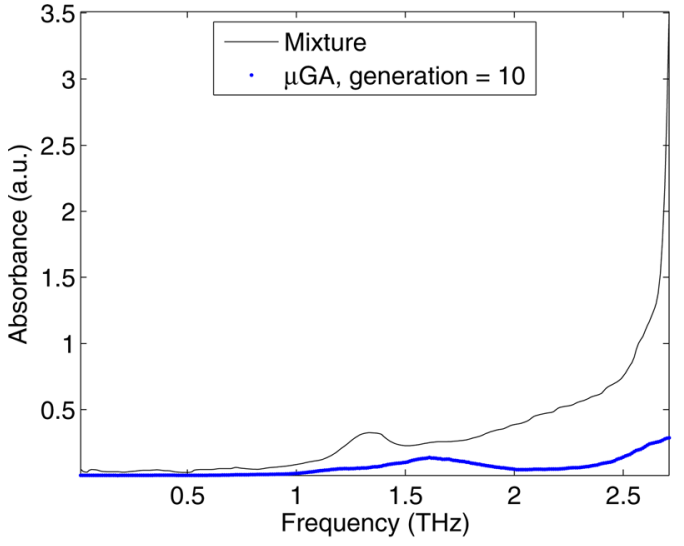

(a) $\mathrm{THz}$ spectra comparison @ generation $=10$

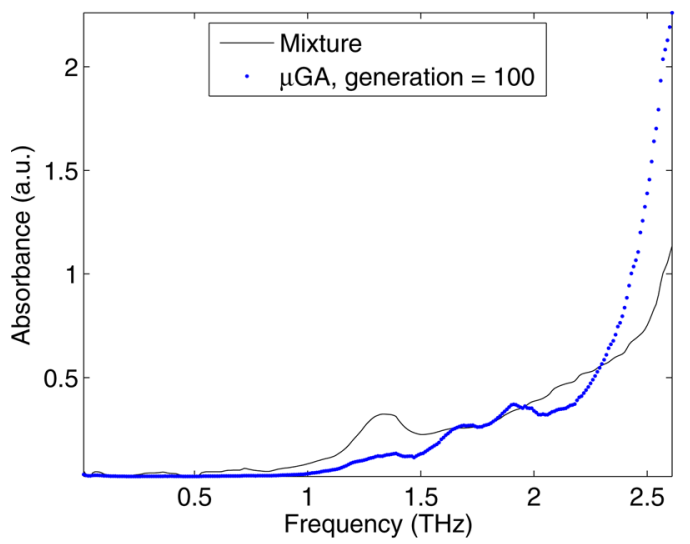

(c) $\mathrm{THz}$ spectra comparison @ generation $=100$

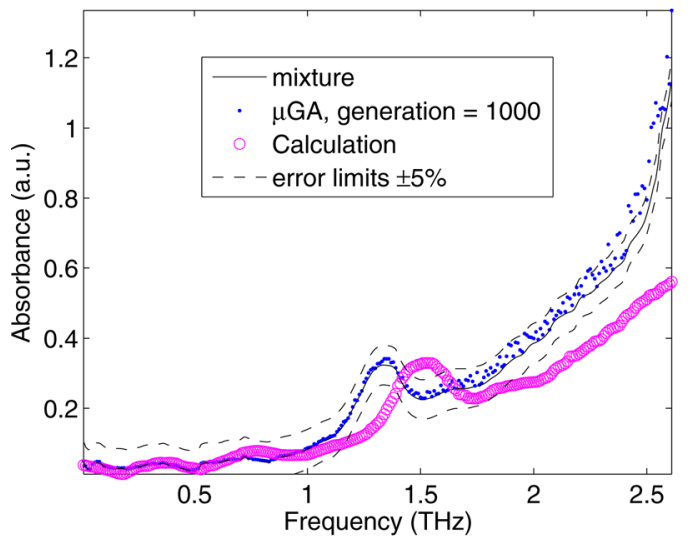

(e) $\mathrm{THz}$ spectra comparison @ generation $=1000$

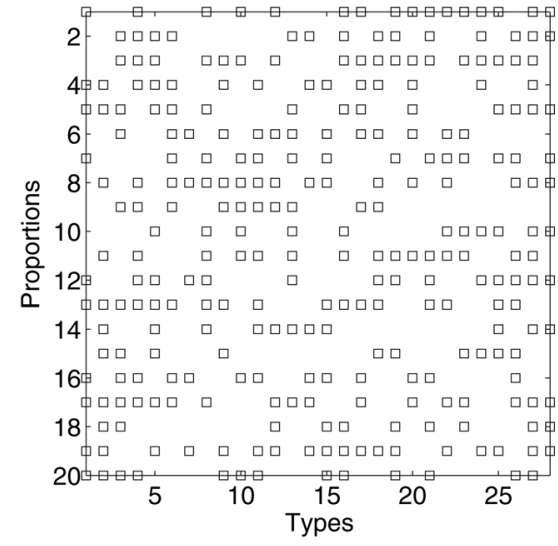

(b)Statement @ generation = 10

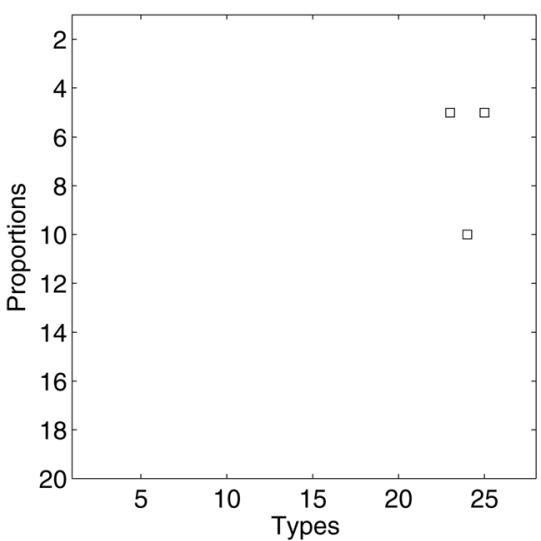

(d)Statement @ generation = 100

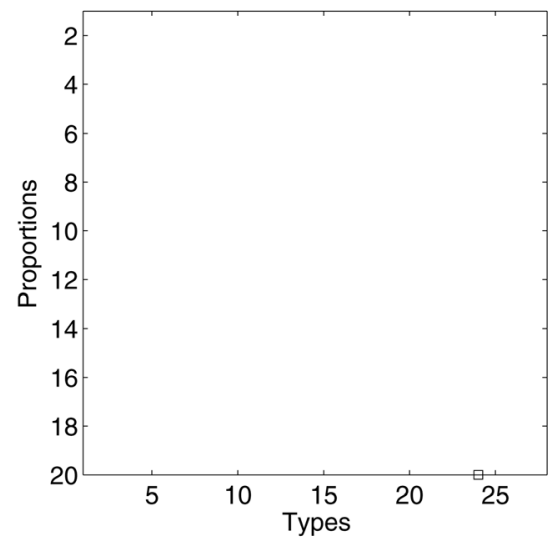

(f)Statement @ generation = 1000
FIG. 8. (Color online) Test 2: calculated statement distribution and corresponding terahertz spectra at various generations: (a),(b) 10 generations, (c),(d) 100 generations, and (e),(f) 1000 generations.

\section{THZ SPECTROSCOPIC DATA AND CASES DESCRIPTION}

A $\mathrm{THz}$ spectroscopic database for this paper is listed in Table I and includes the following: (1) the THz spectroscopic data of the illicit drug samples (MA, MDA, MDMA, and heroin) and the antibiotic samples (phenoxymethylpenicillin penicillin $\mathrm{V}$, amoxicillin) used in this paper, which are obtained from other researchers' work and are recorded experimentally via the THz-TDS system; ${ }^{31-36}$ (2) the explosives and related compounds: 1,3-dinitrobenzene (1,3-DNB), 2,4,6trinitrotoluene (TNT), hexahydro-1,3,5-trinitro-1,3,5-triazine (RDX), pentaerythritol tetranitrate (PETN), octahydro-1,3,5,7tetranitro-1,3,5,7-tetrazocine (HMX), 4-nitrotoluene (4-NT), 2-amino-4,6-dinitrotoluene (2-A-4,6-DNT), 2,4-dinitrotoluene (2,4-DNT), 2,6-dinitrotoluene (2,6-DNT), 4-amino-2,6-dinitrotoluene (4-A-2,6-DNT), 2,4,6-trinitrophenylmethylnitramine (Tetryl), 1,3,5-trinitrobenzene (1,3,5-TNB), 3,5-dinitrotoluene (3,5-DNT), and 2,4-dinitrobenzyl alcohol (2,4-DNB) (Refs. 20, 23, and 41); and (3) benzoic acid, o-toluic acid, m-toluic acid, p-toluic acid, ${ }^{42} \mathrm{D}$-(-)-ribose, D-glucose, $\alpha$-lactose, and $\beta$-lactose. ${ }^{43}$

As given in Table I, there are five cases (Case1-Case5) in this context, in which the mixture samples proportion are $90 \%$ MA; 90\% MDA; 90\% MDMA; 90\% heroin; and 20\% MA, $20 \%$ MDA, 20\% MDMA, 20\% heroin, 10\% penicillin V, and $10 \%$ amoxicillin, respectively. The samples are recorded 


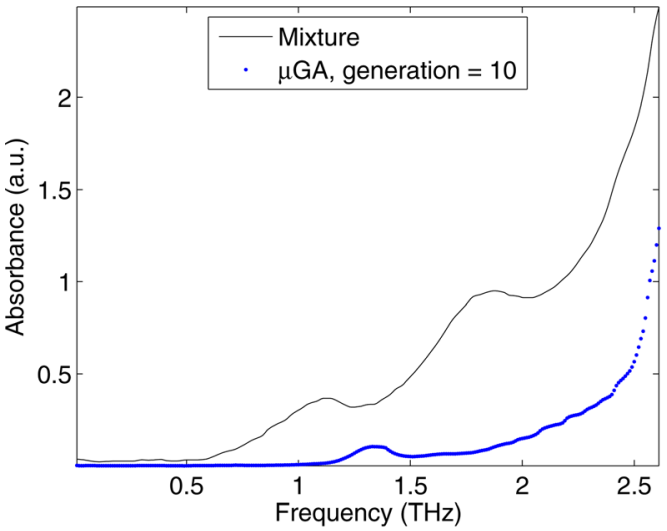

(a) $\mathrm{THz}$ spectra comparison @ generation $=10$

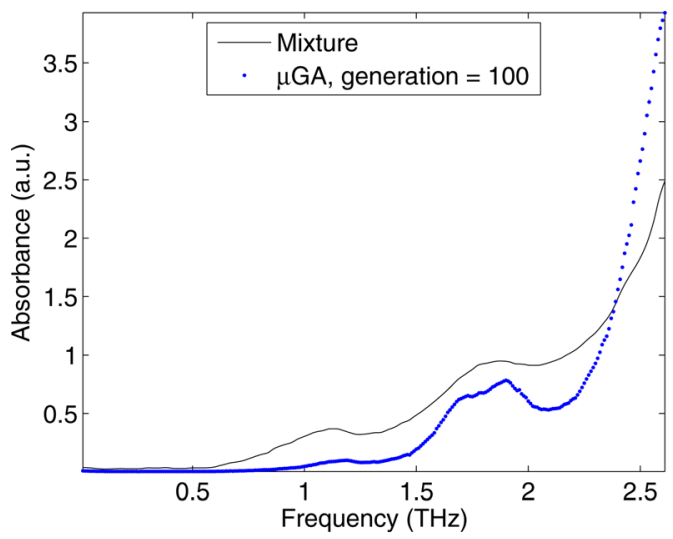

(c) $\mathrm{THz}$ spectra comparison @ generation $=100$

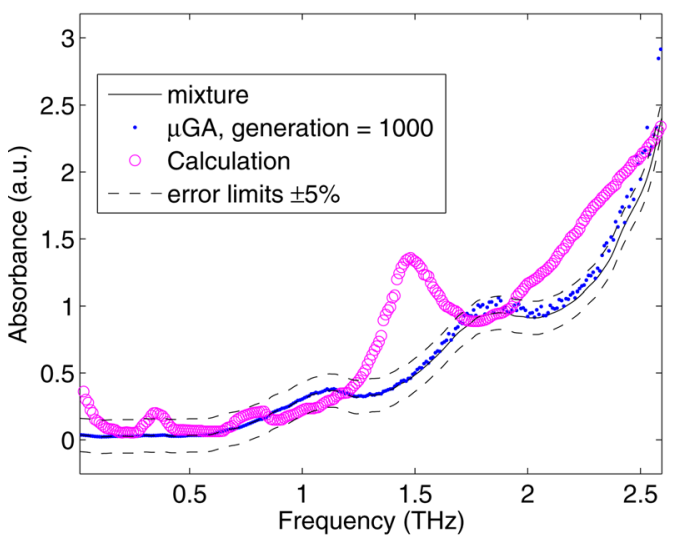

(e) $\mathrm{THz}$ spectra comparison @ generation $=1000$

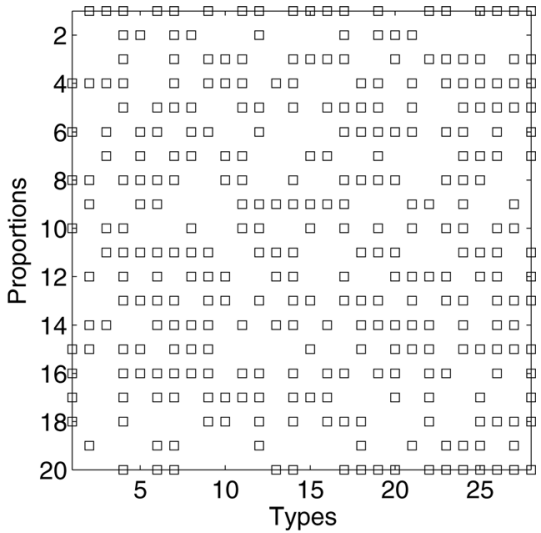

(b)Statement @ generation $=10$

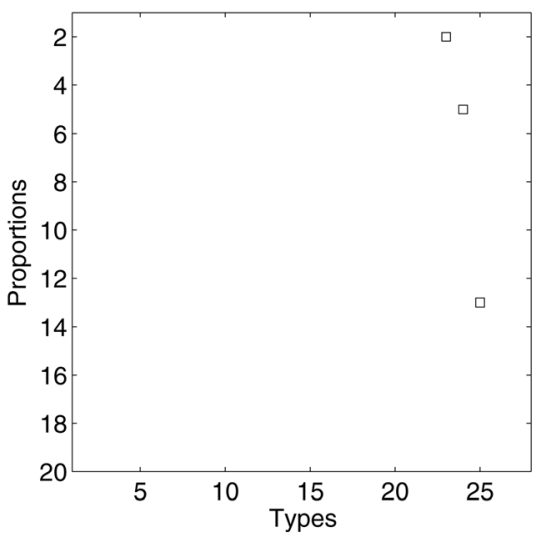

(d)Statement @ generation = 100

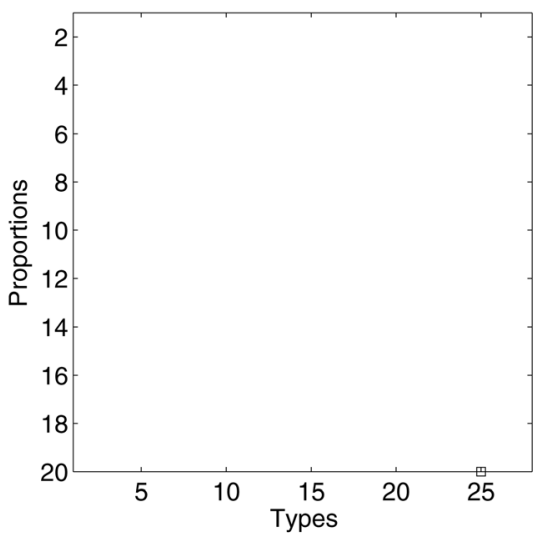

(f)Statement @ generation = 1000
FIG. 9. (Color online) Test 3: calculated statement distribution and corresponding terahertz spectra at various generations: (a),(b) 10 generations, (c),(d) 100 generations, and (e),(f) 1000 generations. experimentally as pellets at different weight ratios; the absorption and dispersions of flour are not exactly the same as in the pure samples, but this imperfection will not interfere with the demonstration of the feasibility of the mixture determination technique discussed in this paper. In Case5, we manually preset a sample mixture containing several drugs and antibiotics that demonstrates the potential applications capable of identifying a complex mixture with more CPU time consumption; in practice, this kind of suspicious drug mixture is difficult to identify visually. The sample spectra are not actual spectral data obtained from experiments as in the previous four cases but are obtained by summing up the weighted spectra of all components in the mixture, as given in Eq. (8).
The noise analysis procedure is given in Fig. 6. In the THz-TDS system, the collected spectroscopic noise data cluster implies the corresponding characteristics of the given drug mixture under different experimental conditions, ${ }^{31-36}$ the "scattering" phenomenon of which has been paraphrased and made ready for the $\mu \mathrm{GA}$ calculation. Basically, but not limited to it, the error handling block can filter the numerical error singularity between the experimental and computational results and generate the error index $\delta_{i}$. Then, if the $\delta_{i}$ is smaller than the given marginal error $\delta_{0}\left(\delta_{i} \leq \delta_{0}\right)$, the results are acceptable for outputs; if $\delta_{i}>\delta_{0}$, the program goes back to the next loop for the mixture components approaching. 


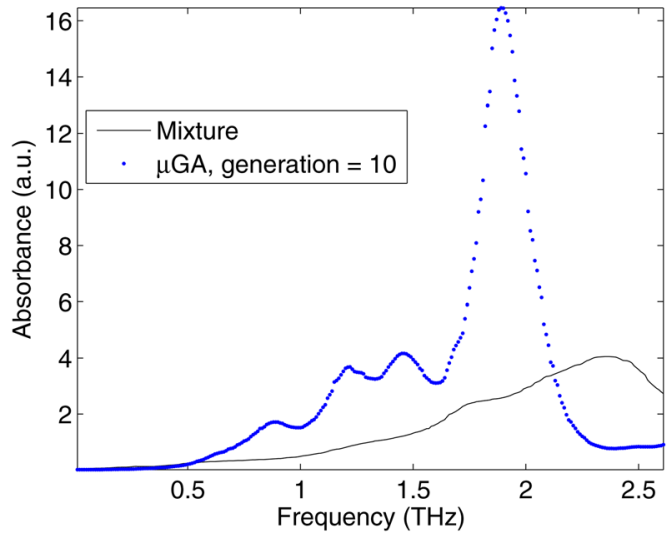

(a) $\mathrm{THz}$ spectra comparison @ generation $=10$

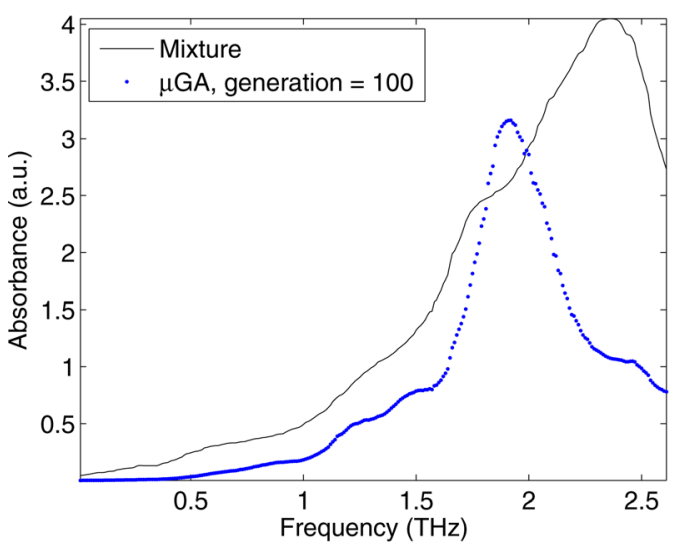

(c) $\mathrm{THz}$ spectra comparison @ generation $=100$

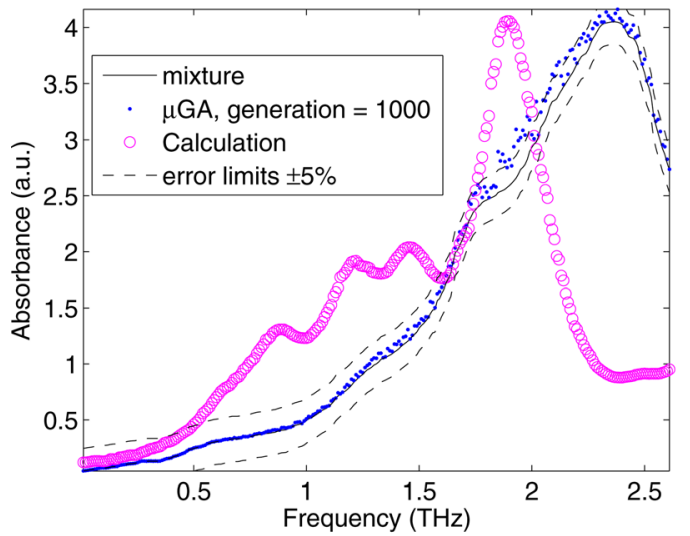

(e) $\mathrm{THz}$ spectra comparison @ generation $=1000$

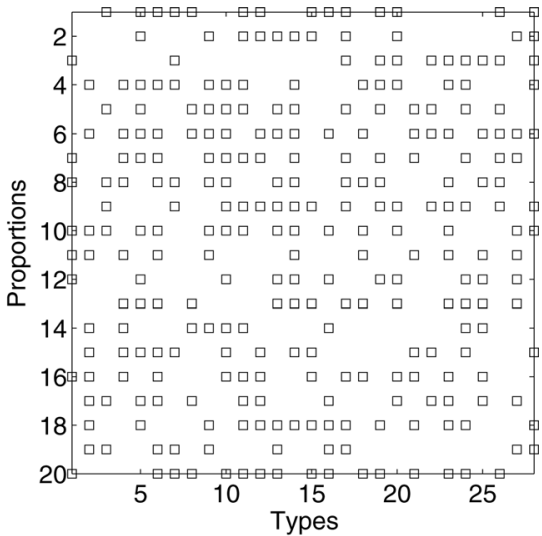

(b)Statement @ generation = 10

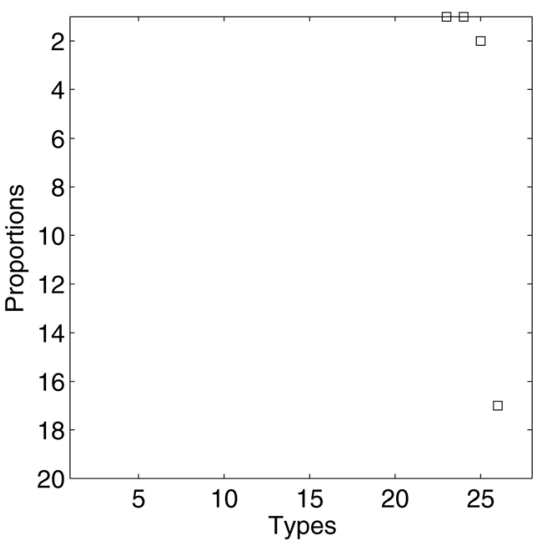

(d)Statement @ generation = 100

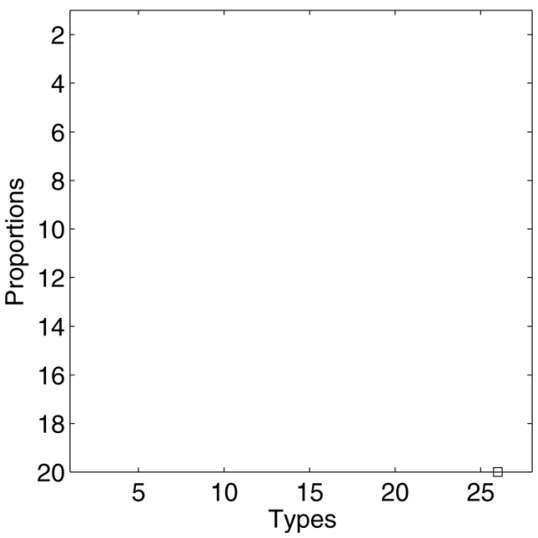

(f)Statement @ generation = 1000
FIG. 10. (Color online) Test 4: calculated statement distribution and corresponding terahertz spectra at various generations: (a),(b) 10 generations, (c), (d) 100 generations, and (e),(f) 1000 generations.

\section{NUMERICAL RESULTS AND DISCUSSION}

There are some parameters that need to be assigned for the ARVIP $\varepsilon \mu \mathrm{GA}$ computing process; these usually include the internal population size $P_{I}$, the external population $P_{E}$, the crossover probability, the mutation probability, the max generations, and the max internal generations, as listed in Table II. Numerical results are obtained using the simulation toolbox for MATLAB, known henceforth here as SGALAB. ${ }^{45}$ Unless otherwise stated, all of the results are generated using the following parameters as listed in Table II for the simulation process, involving binary encoding/decoding methods, tournament selection, and single point crossover.
The computer facilities for the simulations are a 2.1 $\mathrm{GHz}$ Intel dual-core processor, Windows XP Professional v5.01 Build 2600 service pack 3, a $2.0 \mathrm{~GB} 800 \mathrm{MHz}$ dual channel DDR2 SDRAM, MATLAB R2008a, and SGALAB 1.0.0.3 Beta 5008 .

As stated in Table III, the $R^{2}$ comparison for one selected simulation result indicates that the proposed ARVIP $\varepsilon \mu \mathrm{GA}$ method outperformed the previous results as discussed in other researchers' results; $;{ }^{31-36}$ the simulation process is also discussed in Figs. 7-11, which show the statement and corresponding calculated spectra for all cases.

There are three evolutional stages captured at various generation sizes (10, 100, and 1000, as shown in Figs. 7-11); 


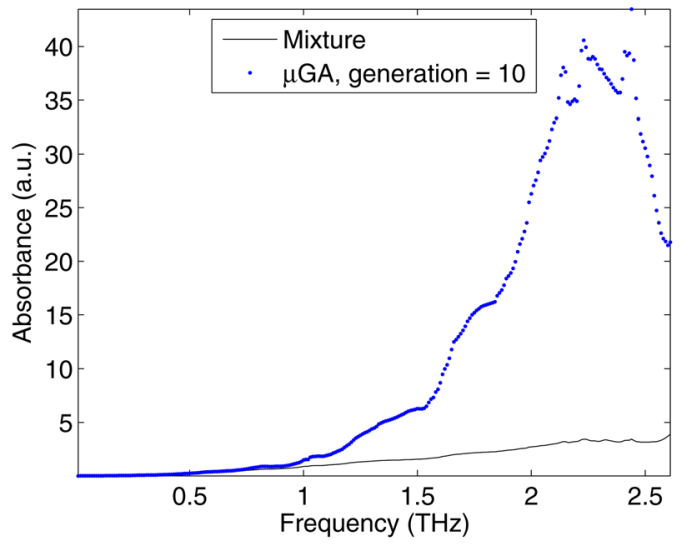

(a) $\mathrm{THz}$ spectra comparison @ generation $=10$

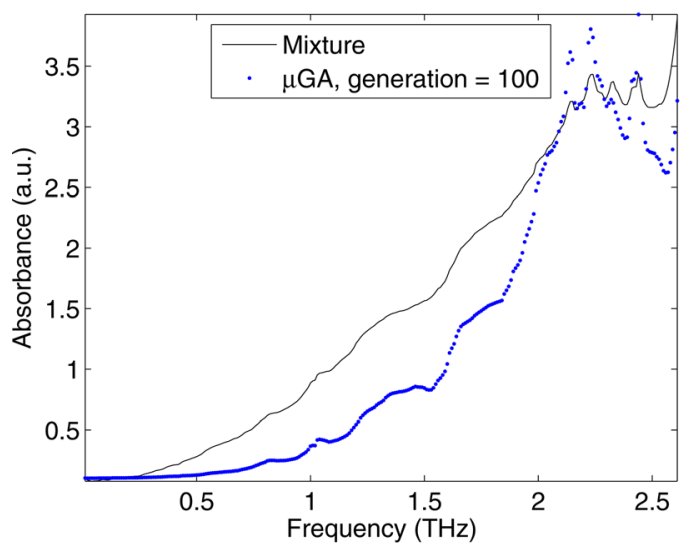

(c) $\mathrm{THz}$ spectra comparison @ generation $=100$

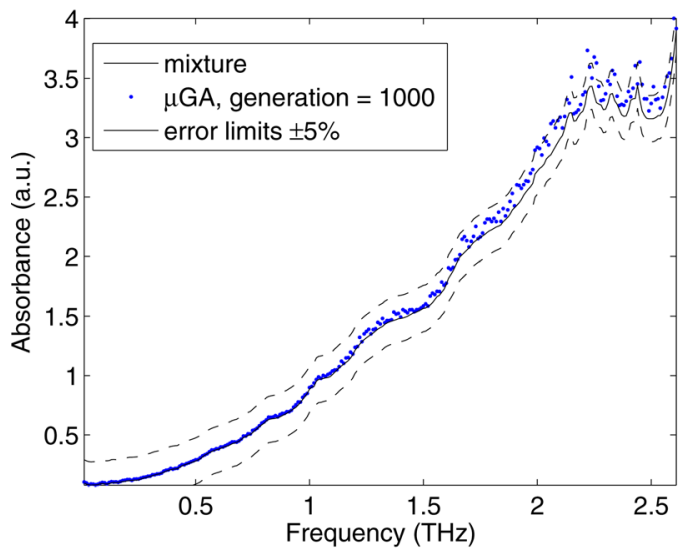

(e) $\mathrm{THz}$ spectra comparison @ generation $=1000$

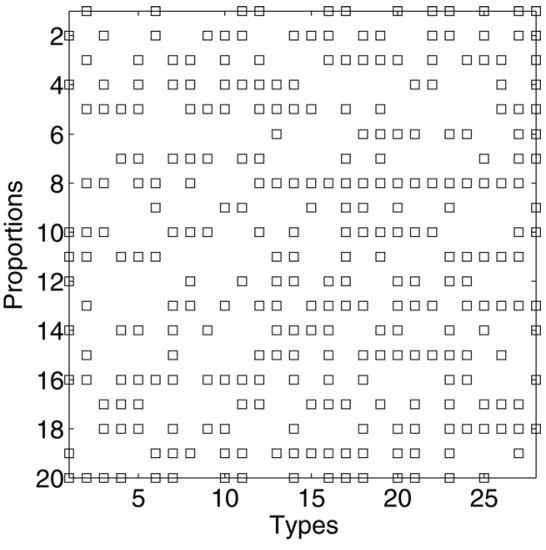

(b)Statement @ generation = 10

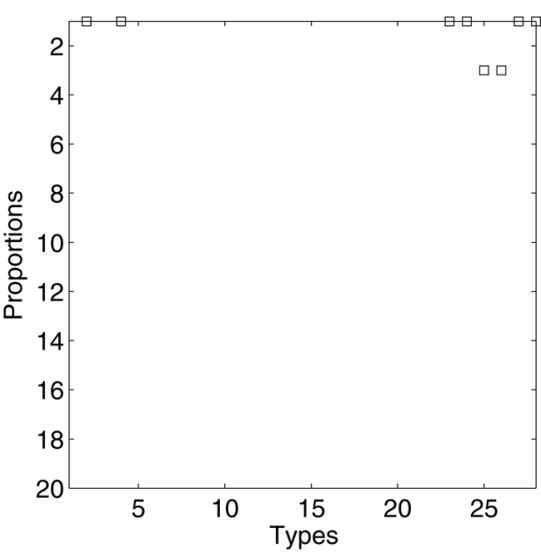

(d)Statement @ generation = 100

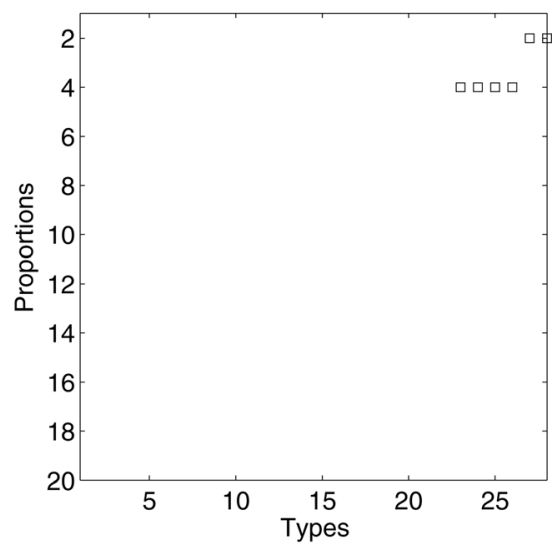

(f)Statement @ generation = 1000
FIG. 11. (Color online) Test 5: calculated statement distribution and corresponding terahertz spectra at various generations: (a),(b) 10 generations, (c), (d) 100 generations, and (e),(f) 1000 generations. when the generation size increases, the mixture spectra obtained by the ARVIP $\varepsilon \mu \mathrm{GA}$ analysis demonstrate better fitting than the experimental spectra.

Figure 7(a) and Fig. 7(b) are the THz spectra comparison and the statement at generation $=10$; Fig. 7(c) and Fig. 7(d) are the $\mathrm{THz}$ spectra comparison and the statement at generation $=100$, which demonstrate that the $\mathrm{THz}$ spectroscopic curves are located closer than they were at generation $=10$. The elements of the statement at generation $=100$ are less than at generation $=10$, which states the clearer possible combinations. Figure 7(e) and Fig. 7(f) are the $\mathrm{THz}$ spectra comparison and the statement at generation $=1000$. The "Calculation" results adapted from Refs. 31-36 are also plotted as circles (' $\bigcirc$ ') in Fig. 7(e), where the $\mu$ GA driven curve (dotted line) stays within the $\pm 5 \%$ error limit (dashed line) relative to the mixture curve (solid line). The statement in Fig. 7(f) indicates the final optimized possible combination of the given mixture.

Similarly, as shown in Figs. 8 to 11 , the results of Case2 to Case5 also demonstrate the agreement between ARVIP $\varepsilon \mu \mathrm{GA}$ and other analytical techniques, which suggests that the ARVIP $\varepsilon \mu \mathrm{GA}$ analysis can precisely determine the components as well as their concentrations in the drug mixture. Also, in parts (e) of Figs. 7 to 11, there are few data scattered out of the error limits, which implies the uncertainty of the evolutional process driven by the ARVIP $\varepsilon \mu \mathrm{GA}$ method 
within an acceptable level, and the few misplacements of the components in a statement with a minimal statement resolution of $5 \%$ can cause a larger $\mathrm{THz}$ spectroscopic data error spread than the figured error limits of $\pm 5 \%$ under the current experimental conditions.

\section{CONCLUSIONS}

An improved $\mu \mathrm{GA}$ has been proposed as $\mathrm{ARVIP} \varepsilon \mu \mathrm{GA}$, which then has been utilized in the quantitative analysis of drug mixtures based on their terahertz spectra. Based on the proposed "statement" concept, the components and their corresponding percentages in the mixture can be analytically identified within error limits. Five study cases of mixtures have been tested under this technical roadmap. Among these cases, four cases have been shown to demonstrate agreement with the experimental results reported in other works. This technique has potential applications for the terahertz spectral identification of chemical mixtures such as explosives and agricultural products.

\section{ACKNOWLEDGMENTS}

The authors would like to acknowledge the partial support provided by the Talent Start-up Grant Scheme of University of Electronic Science and Technology of China (UESTC) (No. Y02002010801052), the Fundamental Research Funds for Central Universities (No. ZYGX2009X013), and the National Natural Science Foundation of China (NSFC) (No. 30872183).

Also, the authors would like to acknowledge the anonymous reviewers and their valuable comments on this paper.

${ }^{1}$ M. Hangyo, M. Tani, T. Nagashima, Int. J. Infrared Millim. Waves 26, 1661 (2005).

${ }^{2}$ C.A. Schmuttenmaer, Chem. Rev. 104, 1759 (2004).

${ }^{3}$ M. Walther, B. Fischer, M. Schall, H. Helm, and P. U. Jepsen, Chem. Phys. Lett. 332(3-4), 389 (2000).

${ }^{4}$ Y. J. Ding and W. Shi, J. Nonlinear Opt. Phys. Mater. 15(1), 89 (2006).

${ }^{5}$ S. Hargreaves and R. A. Lewis, J. Mater. Sci.: Mater. Electron. 18, 299 (2007).

${ }^{6}$ A. Schneider, M. Stillhart, and P. Günter, Opt. Express 14(12), 5376 (2006).

${ }^{7}$ A. Nahata, A. S. Weling, and T. F. Heinz, Appl. Phys. Lett. 69(16), 2321 (1996).

${ }^{8}$ N. Katzenellenbogen and D. Grischkowsky, Appl. Phys. Lett. 58(3), 222 (1991).

${ }^{9}$ J. Mangeney and P. Crozat, C. R. Phys. 9(2), 142 (2008).

${ }^{10}$ Y. Watanabe, K. Kawase, T. Ikari, H. Ito, Y. Ishikaw, and H. Minamide, Opt. Commun. 234(1-6), 125 (2004).

${ }^{11}$ G. P. Gallerano, "THz-bridge," Quality of Life and Management of Living Resources Key Action 4-Environment and Health, Final Report QLK4CT-2000-00129, 2004.

${ }^{12}$ B. Ferguson and X. Zhang, Nat. Mater. 1, 26 (2002).

${ }^{13}$ K. Yamamoto, M. Yamaguchi, F. Miyamaru, M. Tani, M. Hangyo, T. Ikeda, A. Matsushita, K. Koide, M. Tatsuno, and Y. Minami, Jpn. J. Appl. Phys. 43, 414 (2004).

${ }^{14}$ K. Kawase, Y. Ogawa, and Y. Watanabe, Opt. Express 11, 2549 (2003).

${ }^{15}$ H. Q. Wu, E. J. Heilweil, A. S. Hussain, and M. A. Khan, Int. J. Pharm. 343, 148 (2007).

${ }^{16}$ J. H. Son, J. Appl. Phys. 105(10), 102033 (2009).
${ }^{17}$ Y. Ueno and K. Ajito, Anal. Sci. 24(2), 185 (2008).

${ }^{18}$ T. Kanamorit, K. Tsujikawa, Y. T. Iwata, H. Inoue, O. Ohtsuru, T. Kishi, H. Hoshina, C. Otani, and K. Kawase, "Application of terahertz spectroscopy to abused drug analysis," in The Joint 30th International Conference on Infrared and Millimeter Waves and 13th International Conference on Terahertz Electronics, IRMMW-THz 2005, Williamsburg, Virginia, 19-23 September 2005, (IEEE, Piscataway, NJ, 2005), Vol. 1, pp. 180-181.

${ }^{19}$ P. F. Taday, Philos. Trans. R. Soc. London 362, 351 (2004).

${ }^{20}$ A. G. Davies, A. D. Burnett, W. Fan, E. H. Linfield, and J. E. Cunningham, Mater. Today 11(3), 18 (2008).

${ }^{21}$ A. Burnett, W. H. Fan, P. Upadhya, J. Cunningham, H. Edwards, T. Munshi, M. Hargreaves, E. Linfield, and G. Davies, Proc. SPIE 6402, 64020B (2006).

${ }^{22}$ D. J. Cook, B. K. Decker, and M. G. Allen, "Quantitative thz spectroscopy of explosive materials," in Optical Terahertz Science and Technology, Technical Digest (CD), paper MA6 (Optical Society of America, Washington, D.C., 2005).

${ }^{23}$ H. B. Liu and X. C. Zhang, "Terahertz spectroscopy for explosive, pharmaceutical, and biological sensing applications," in Terahertz Frequency Detection and Identification of Materials and Objects, edited by R. E. Miles, X. C. Zhang, H. Eisele, and A. Krotkus (Springer, New York, 2007), pp. 251-323.

${ }^{24} \mathrm{~K}$. Krishnakumar, "Micro-genetic algorithms for stationary and non-stationary function optimization," in SPIE: Intelligent Control and Adaptive Systems (Philadelphia, PA, 1989), Vol. 1196, pp. 289-296.

${ }^{25}$ G. Abu-Lebdeh and R.F. Benekohal, Comput. Aided Civ. Infrastruct. Eng. 14, 321 (1999).

${ }^{26}$ C. A. Coello Coello and G. T. Pulido, "A Micro-genetic algorithm for multiobjective optimization," in Proceedings of the Genetic and Evolutionary Computation Conference (Springer-Verlag, Berlin, 2001), pp. 126-140.

${ }^{27}$ K. L. Lo and L. Khan, 151(1), 109 (2004).

${ }^{28}$ V. Tam, K. Y. Cheng, and K. S. Lui, J. Commun. 1(4), 1 (2006).

${ }^{29}$ O. Davidyuk, I. Selek, J. Ceberio, and J. Riekki, “Application of microgenetic algorithm for task based computing," in Proceedings of the International Conference on Intelligent Pervasive Computing (IPC-07), Jeju Island, Korea, October 2007 (IEEE, Piscataway, NJ, 2007), pp. 140-145.

${ }^{30}$ A. Szőllös, M. Smíd, and J. Hájek, 40(6), 419 (2009).

${ }^{31}$ N. Li, J. L Shen, J. H Sun, L. S. Liang, X. Y. Xu, M. H. Lu, and Y. Jia, Opt. Express 13(18), 6750 (2005).

${ }^{32}$ Y. Jia, N. Li, M. H. Lu, J. H. Sun, Y. N. Shi, X. Y. Xu, L. S. Liang, and J. L Shen, Modern Scientific Instruments 2, 41 (2006).

${ }^{33}$ Y. Jia, S. J. Chen, N. Li, M. H. Lu, D. J. Jiang, G. Q. Wang, and J. L. Shen, Chin. J. Lasers 34(5), 719 (2007).

${ }^{34} \mathrm{~N}$. Li, "Terahertz spectroscopy of illicit drug and western medicines," Master's thesis, Department of Physics, Capital Normal University, 2007.

${ }^{35}$ Y. Jia, "Thz wave its application in drug and antibiotics identification by SOM neural networks," Master's thesis, Department of Physics, Capital Normal University, 2007.

${ }^{36}$ T. He, J. L. Shen, and M. Y. Liang, Measurement 44, 391 (2010).

${ }^{37}$ E. J. Heilweil and M. Campbell, "THz spectral database," available at http://webbook.nist.gov/chemistry/thz-ir (2011).

${ }^{38}$ Tera-Photonics Team, RIKEN Sendai, "THz database 2.0," available at http://www.riken.jp/THzdatabase/(2011).

${ }^{39}$ D. C. Montgomery and G. C. Runger, Applied Statistics and Probability for Engineers, 3rd ed. (John Wiley \& Sons, New York, 2003).

${ }^{40}$ D. N. Gujarati, Basic Econometrics, 4th ed. (McGraw-Hill, New York, 2004).

${ }^{41}$ S. D. Harvey, R. J. Fellows, J. A. Campbell, and D. A. Cataldo, J. Chromatogr. A 605(2), 227 (1992).

${ }^{42}$ Z. Y. Zhang, T. Ji, X. H. Yu, T. Q. Xiao, and H. J. Xu, Chin. Phys. Lett. 23(8), 2239 (2006).

${ }^{43}$ X. J. Ma, H. W. Zhao, G. F. Liu, T. Ji, Z. Y. Zhang, and B. Dai, Spectrosc. Spectral Anal. (Beijing) 29(11), 2885 (2009).

${ }^{44}$ J. H. Sun, J. L. Shen, L. S. Liang, X. Y. Xu, H. B. Liu, and C. L. Zhang, Chin. Phys. Lett. 22, 3176 (2005).

${ }^{45}$ Y. Chen, "Simple genetic algorithm laboratory toolbox for matlab," available at http://www.mathworks.co.uk/matlabcentral/fileexchange/5882. 